\title{
Aplicaciones de los métodos mixtos al análisis de las redes personales de la población inmigrada ${ }^{1}$
}

\author{
Mixing methods in Social Network Analysis: Applications \\ to the analysis of migrants' personal networks.
}

\author{
Mireia Bolíbar, Joel Martí, Carlos Lozares
}

Centre d'Estudis Sociològics sobre la Vida Quotidiana i el Treball (QUIT)

Universitat Autònoma de Barcelona

Mireia.Bolibar@uab.cat (ESPAÑA)

Recibido: 13.012012

Aceptado: 28.04.2013

\section{RESUMEN}

Este artículo muestra los beneficios del uso de métodos mixtos en el análisis de redes sociales. Para ello, en primer lugar, se identifican los diferentes objetivos, diseños y supuestos de dicha combinación metodológica. En segundo lugar, se ejemplifica el potencial de los diseños mixtos presentando una investigación empírica que analiza el impacto y vinculación entre la participación en asociaciones y el proceso de integración de la población inmigrada en Cataluña (visto a través de sus redes sociales). Dicha vinculación es especialmente fructífera mediante el uso de métodos mixtos; concretamente, el estudio combina el análisis de las estructuras de las redes personales con sus significados y dinámica, lo que permite explicar los diferentes procesos de asentamiento de la población inmigrada y el papel que juega en ellos la participación en asociaciones.

\section{PALABRAS CLAVE}

Redes sociales, métodos mixtos, inmigración, integración, participación.

${ }^{1}$ Este artículo proviene de una investigación que tiene como referencia CSO2008-01470, financiada por el MiCINN dentro del marco del VI Plan Nacional de Investigación Científica, Desarrollo e Innovación Tecnológica 2008-2011. 


\begin{abstract}
This article shows the benefits of the use of mixed methods in social network analysis. Firstly, it reviews the use of mixed methods in this particular field, indentifying the different objectives and designs used for the combination of methods. Secondly, the potential of mixed methods is exemplified through an empirical research that analyzes the impact of participation in associations on personal networks and on the integration process of migrant population in Catalonia, Spain. Specifically, this study combines the analysis of personal networks structures with its meanings and dynamics, which allows to explain the different migrant's processes of settlement in the host society, and the role that participation in associations plays on them.
\end{abstract}

\title{
KEYWORDS
}

Social networks, mixed methods, migration, integration, participation.

\section{INTRODUCCIÓN}

El desarrollo y consolidación del análisis de redes (ARS) en ciencias sociales ha ido de la mano de los progresivos avances en los procedimientos formales y el álgebra que lo caracterizan. Con todo, el estudio de redes mediante métodos cualitativos está en las propias raíces antropológicas del ARS (Barnes 1954; Bott 1957) y, en contribuciones más recientes, estos métodos se han aplicado a campos como el estudio de la relación entre redes de apoyo y movilidad social (Domínguez 2004, 2008), la evolución de las redes personales en la transición a la vida adulta (Bidart y Lavenu 2005), la identificación de los límites de la red personal (Heath, Fuller y Johnson 2009), el significado de las relaciones familiares y de amistad (Pahl y Spencer 2004) o las redes de actores locales (Villasante y Martín 2006). Algunas publicaciones van en la dirección de sistematizar las aportaciones de los métodos cualitativos al estudio de las redes (por ejemplo, Hollstein 2011), mientras que en otras se propone la denominación de qualitative social network analysis (QSNA) para hacer referencia a estas aproximaciones (Heath et al. 2009: 646). Un tercer conjunto de trabajos, en el que se centra este artículo, se caracterizan por integrar métodos cuantitativos y cualitativos en el análisis de redes o bien por conceptualizar esta integración (Bellotti 2010, 2011; Crossley 2010a, 2010b; Edwards 2011; Fuhse y Mützel 2011; Hollstein 2011; además de un manual de próxima publicación editado por Silvia Dominguez y Betina Hollstein). A partir de la revisión de estas contribuciones, el artículo presenta un análisis de las redes personales de población inmigrada mediante métodos mixtos, con el que se persigue tanto el análisis sustantivo de los vínculos entre redes sociales, discurso y participación asociativa como ejemplificar las 
diferentes formas de aplicación y los beneficios de la combinación de métodos en el estudio de las relaciones sociales.

\section{LOS MÉTODOS MIXTOS EN EL ANÁLISIS DE REDES SOCIALES, UN RECORRIDO POR LA LITERATURA}

\section{¿Es deseable la integración cuanti-cuali en redes?}

Desde la tesis de la incompatibilidad entre paradigmas (ver Pardo 2011 para un mayor desarrollo de esta cuestión) algunos autores cuestionan la pertinencia de integrar el ARS con una perspectiva cualitativa. Así, desde el interaccionismo simbólico, Salvini plantea que esta integración metodológica es «problemática, si no completamente improbable» (2010: 365), debido a los supuestos realistas del ARS y el énfasis explicativo otorgado a las estructuras de relaciones; para este autor, el estudio de cómo las personas producen y reproducen simbólicamente estas estructuras y del rol de los significados en este proceso implicaría el uso prioritario de métodos cualitativos (2010: 374).

Frente a esta postura, las posiciones favorables a la integración metodológica (Bellotti 2011; Crossley 2010a; Edwards 2010; Fuhse y Mützel 2011; Hollstein 2011; Jack 2010; Kirke 2010; McCarty 2010; Mische 2003; Bidart y Cacciuttolo, 2012) tienden a situarse en torno a dos argumentos: (a) que los métodos cualitativos juegan un papel complementario a los cuantitativos, aportando riqueza informativa al uso central de procedimientos estandarizados que permiten medir las propiedades de la red, de los actores que la componen y de los cambios en las posiciones y estructuras; o bien (b) que mientras los métodos cuantitativos se orientarían al estudio de la estructura de relaciones y a las posiciones que los actores ocupan en ellas, los cualitativos apuntarían a la comprensión del significado atribuido a dichas relaciones y al estudio de los procesos de interacción. El primer argumento correspondería a lo que podemos llamar una «versión débil» de integración, en la que el método predominante es el cuantitativo. El segundo argumento, que encuentra sus raíces en la tradición cualitativa en ciencias sociales, en la sociología relacional de Harrison White (1992) y la corriente culturalista del ARS (ver Mützel, 2009 o Knox, Savage y Harvey 2006 para una revisión sobre el «giro cultural» en redes), focaliza su interés en el vínculo entre significados y relaciones, y plantea diseños en los que los métodos cualitativos comparten centralidad con los cuantitativos.

En este artículo sostenemos que el uso de métodos mixtos en los análisis de redes es pertinente en una diversidad de diseños en los que cuantitativo y cualitativo pueden tener distintos objetivos y centralidad en la investigación. Esta diversidad es señalada especialmente en los textos de Edwards (2011), Fuhse y Mützel (2011) y Hollstein (2011), cuyas contribuciones permiten constatar cómo ambos métodos pueden usarse de forma combinada en (1) el estudio de la estructura y las posiciones de la red, (2) los significados de las relaciones y (3) la dinámica y evolución de la red; así como en la articulación de estos objetos de estudio. 


\section{La estructura y posiciones de la red}

El estudio de la estructura de relaciones y de las posiciones que los actores ocupan en la red así como la vinculación entre propiedades estructurales y atributos individuales son algunos de los aspectos que tradicionalmente han recibido más atención del ARS. Siendo estos objetos tradicionalmente tratados desde una óptica cuantitativa, una estrategia combinada se justifica en, al menos, cinco situaciones ya señaladas por Hollstein (2011): (a) para delimitar el campo de observación e identificar situaciones y casos de estudio (ver Curtis et al. 1995); (b) para apoyar el diseño de los indicadores que se utilizarán en un cuestionario sociométrico (McCarty 2010: 4); (c) para validar los indicadores y datos obtenidos por procedimientos cuantitativos (ver Lubbers y otros 2010: 95 y Armitage 2011); ${ }^{2}$ (d) para focalizar el análisis en casos específicos después de una primera fase cuantitativa y extensiva (ver Wong y Salaff 1998); y (e) para obtener datos cuando resulta excesivamente complejo hacerlo de forma estandarizada - recurriendo entonces a procedimientos más inductivos como preguntas de respuesta abierta (Kirke 2010:9) o entrevistas semi-estructuradas (Coviello 2005; McKether, Gluesing y Riopelle 2009) cuya información es posteriormente codificada para ser analizada mediante el álgebra del ARS.

\section{Los significados de las relaciones}

La combinación de datos cuantitativos de estructuras reticulares con datos cualitativos sobre el significado atribuido a las relaciones no es nueva en el ARS (ver Emirbayer y Goodwin 1994; White 1992) y sigue muy presente en la literatura sobre métodos mixtos aplicados al ARS. En esta dirección pueden inscribirse los análisis de Keim, Klärner y Bernardi (2009) sobre cómo la decisión de tener hijos se plantea solo cuando los egos evalúan positivamente los alteri con hijos de su red y los de Bellotti (2008) sobre las estructuras de apoyo social y su relación con el significado atribuido a la «amistad». Esta complementariedad entre estructura y significado es extensible al análisis de redes sociocéntricas, relacionando las propiedades de la red completa con los discursos o significados compartidos de los actores que la componen (Fuhse y Mützel 2011: 1083-4).

Por otro lado, la codificación numérica de significados atribuidos a las relaciones por medios cualitativos permite que éstos puedan introducirse en análisis cuantitativos. Las mencionadas observaciones de Kirke (2010: 9) sobre las preguntas abiertas son igualmente aplicables aquí; por lo demás, se trata de técnicas de formalización de información cualitativa extensibles por ejemplo al análisis de redes textuales (Carley 1997; Lozares, Verd, Martí y López Roldán 2003).

\footnotetext{
2 Incluso se han desarrollado programas informáticos como VennMaker (www.vennmaker. com/en) que permiten el registro simultáneo de información cuantitativa y cualitativa para complementar ambos tipos de información y posibilitar su aplicación en investigación participativa.
} 


\section{Lo longitudinal y dinámico}

Como señala De Federico (2005: 151), el ARS ha pasado de centrarse en la estructura como factor explicativo de la acción a extender su interés hacia la emergencia y evolución de las relaciones, que son explicadas por la acción de los actores. Ello ha sido acompañado, especialmente en los últimos años, del desarrollo de modelos formales de análisis longitudinal (Snijders 2005). Por otro lado, la dinámica inductiva y el carácter situado que caracteriza los métodos cualitativos se argumenta como pertinente para detectar los factores que están interviniendo en los cambios y cómo lo están haciendo; para Crossley, aunque estos factores se puedan introducir como parámetros en un modelo, una aproximación cualitativa permite detectar aquellos que son significativos «en un mundo social específico» (2010a: 28) y en el marco de un relato narrativo («story») (2010a: 12-13).

Entre los diseños que integran métodos cualitativos en el análisis del cambio en las redes pueden distinguirse dos enfoques. Por un lado, los trabajos que contemplan la observación de la red en dos o más estados temporales y que utilizan los datos cualitativos para explicar estos cambios desde la narración de los actores (ver, por ejemplo, Lubbers et.al. 2010, donde los factores de cambio identificados en entrevistas cualitativas son posteriormente introducidos en el modelo cuantitativo). Por otro, los trabajos que se centran en el estudio de los procesos de interacción para explicar los mecanismos conversacionales mediante los cuales se (re)producen las relaciones identificadas mediante el ARS (Mische 2003).

En definitiva, el repaso de la literatura existente nos permite observar cómo el uso de métodos mixtos permite enriquecer el estudio de cada una de estas dimensiones de las redes (estructura, significados y dinámica). Con el objetivo de mostrar la pertinencia de la combinación metodológica, en este artículo ejemplificamos con una investigación empírica cómo el uso de métodos mixtos permite articular un análisis que integre coherentemente estas diferentes dimensiones.

\section{PRESENTACIÓN DE LA INVESTIGACIÓN CIENTÍFICA}

La investigación que presentamos en este artículo tiene como objetivo analizar el proceso de integración de la población inmigrada ecuatoriana y marroquí en Cataluña, y ver específicamente el papel de la participación en asociaciones en dicha integración.

\section{La integración social desde la perspectiva de redes}

Nos referimos a la integración social de la población inmigrada como el proceso de incorporación en un sistema (la sociedad de acogida) de elementos externos a él (las personas y grupos de inmigrantes) (Bauböck, 1994; Lozares et.al., 2011). En este caso nos fijamos en la integración relacional, es decir, el proceso de interacción y establecimiento de relaciones sociales de la población 
inmigrada con la sociedad de acogida. Este proceso es diverso y puede tomar diferentes formas.

El análisis de las redes sociales ha sido ampliamente utilizado para el estudio de la integración social (Gualda 2004; Hagan 1998; Hope, Edwards, Goulbourne y Solomos 2007; Lozares, Verd, Martí, López Roldán y Molina 2011; Lubbers, Molina y McCarty 2007, Lubbers et al. 2010; Maya 2001; Miguel, Solana y Pascual 2007; Molina, Lerner y Gómez Mestres 2008; Pedone 2010; Portes y Rumbaut 2010), destacando la atención a tres componentes que la definen (la composición étnica de las redes, su distribución geográfica, y su «localización» temporal), y que reflejan diferentes dinámicas presentes en los procesos de integración.

En primer lugar, el proceso de asimilación (de ruptura con el país de origen y de aculturación en la sociedad de destino - Alba y Nee 1999; Rumbaut 1999-) supondría la pérdida del contacto exclusivo con co-étnicos y el desarrollo de vínculos con la población autóctona (Molina et.al. 2008). En cambio, los procesos de etnicidad reactiva y el mantenimiento de los rasgos culturales propios supondrían la creación de sociedades multiculturales y de enclaves étnicos específicos (Portes y Rumbaut 2010) que se plasmarían en redes étnicas homofílicas (Molina et.al. 2008). Finalmente, siguiendo la perspectiva transnacional (Glick Schiller 2008) que comprende las migraciones más allá de los límites fronterizos de los Estados-nación y plantea una concepción multilocal de las mismas que señala la presencia de las personas inmigradas (y sus redes) en múltiples sociedades, cabe distinguir la dimensión espacial y temporal de las relaciones como expresión del proceso migratorio (Molina et.al. 2008). De esta forma, la distinción del lugar de residencia de los alteri entre las personas que residen en el país de origen del ego o bien en la sociedad de acogida, permite diferenciar aquellas relaciones de tipo transnacional de las que expresan la formación y existencia de un enclave étnico (Molina et.al. 2008). Por último, la importancia de las cadenas migratorias (Pedone 2002) y las redes transnacionales de movilidad internacional, visibles en aquellas relaciones con alteri que residen en la sociedad de acogida conocidos en el país de origen, también son un elemento clave en la formación de las redes de la población inmigrada.

\section{El papel de la participación asociativa en las redes sociales de la población inmigrada}

El asociacionismo y la participación en organizaciones, movimientos sociales u otros grupos y formas asociativas de la sociedad civil son un ámbito de socialización dentro del marco de la comunidad local en que se desarrollan (Wollebák y Selle 2004) y al mismo tiempo una fuente de recursos relacionales para la población inmigrada. Por este motivo, la literatura pone de relieve el papel de las asociaciones en la generación de redes que amplían las fuentes informales de apoyo social, apoyo tanto de tipo afectivo o expresivo - es decir, el «imperativo afectivo» o la necesidad humana de encontrarse, reunirse, dialogar, intercambiar afectos, inquietudes y experiencias (Morell, 2005), que limita un marco de pertenencia (Lluch 1998)_; o apoyo de tipo instrumental, mediante el cual se 
crean redes de solidaridad (Sipi 2000), que actúan como protección en caso de necesidad (Garreta 1998).

Sin embargo, existe un debate en el que Glanville (2004) y Lauer y Yan (2010) distinguen entre las «teorías de la integración» y las «teorías del enclave». Las primeras destacan cómo el asociacionismo puede llevar resultados positivos, a través de un círculo virtuoso de creación de redes de confianza (Putnam 1993, 2000), y con un potencial desarrollo de redes diversas, múltiples y superpuestas que proveen oportunidades de interacción entre diferentes segmentos de una comunidad (Wollebaek y Selle 2004; Babchuk y Edwards 1965, Olsen 1982, cit. en Glanville 2004). La realidad que trata de explicar la teoría del enclave considera que las asociaciones pueden reforzar el repliegue étnico y la homofília (Feld 1982; McPherson y Smith-Lovin 1987; y Popielarz y McPherson 1995), incrementado la homogeneidad y endogamia en las redes (Molina et.al., 2008) y creando estructuras paralelas sin contacto con las existentes que producen un efecto de «guetización asociativa» de la minoría (Morell 2005); aunque puede también reforzar las identidades mutuas, y el apoyo social. No obstante, Glanville (2004), Lauer y Yan (2010) y Bolíbar (2011), destacan la diversidad y pluralidad existente en el mundo asociativo, y señalan que el efecto que la participación asociativa sobre las redes puede variar en función del tipo de asociación que se considere.

El estudio de las redes personales que se propone a continuación tiene precisamente como objetivo el análisis de la influencia o correspondencia que se da entre la participación en asociaciones y la integración relacional.

\section{DISEÑO}

Este trabajo forma parte del proyecto «Estudio comparado de casos sobre la influencia mutua entre capital e integración sociales y la inserción, estabilidad, promoción y cualificación en el empleo» (CASREDIN), en cuyo marco realizamos una encuesta de redes personales ${ }^{3}$. Ésta consta de una muestra comparativa de diferentes perfiles de población de tres ciudades de Cataluña: Barcelona, Sant Feliu de Llobregat y Balaguer (ciudades de diferente tamaño que recogen la diversidad urbana del territorio catalán). En este artículo nos centramos específicamente en una sub-muestra formada por 153 personas adultas, nacidas en Marruecos y Ecuador. La elección de estas dos nacionalidades extracomunitarias se justifica por su gran presencia en la sociedad catalana ${ }^{4}$ y por recoger cierta diversidad geográfica, lingüística y religiosa. Por lo que se refiere al procedimiento (2011).

${ }^{3}$ Para mayor detalle sobre el diseño metodológico de la investigación, consultar Lozares et.al.

${ }^{4}$ El colectivo latinoamericano es el más numeroso (dentro del cual el ecuatoriano es el más presente - supone el $6,57 \%$ de la población inmigrada en Cataluña-), mientras que la nacionalidad marroquí es la mayoritaria entre el colectivo inmigrante (el 19,52\% sobre el conjunto de la población extranjera). Datos del 2010. Fuente: Idescat, explotación estadística del Padrón.

EMPIRIA. Revista de Metodología de Ciencias Sociales. N. ${ }^{\circ}$ 26, julio-diciembre, 2013, pp. 89-116. ISSN: 1139-5737, DOI: 10.5944/empiria.26.7154 
de selección de los casos, las únicas cuotas establecidas en esta sub-muestra han sido, a parte de los colectivos de origen, las relativas a los tres municipios indicados. Con todo, en uno de los municipios, dado su pequeño tamaño, no fue posible completar la cuota de población ecuatoriana, por lo que 10 casos fueron substituidos por población boliviana, dominicana y brasileña. La tabla 1 muestra la composición demográfica de la sub-muestra analizada y su comparación con la población de referencia. Aunque, para el caso del colectivo marroquí, la población con un mayor nivel de estudios está sobre-representada y la población con menor nivel de estudios infra-representada, exceptuando la leve presencia de la población de más de 45 años, no existen sesgos significativos con la distribución de la muestra para las variables de sexo y edad.

Tabla 1. Comparación de la muestra con el conjunto poblacional

\begin{tabular}{lccccc}
\hline & \multicolumn{2}{c}{ DATOS } & & MUESTRA \\
\hline $\begin{array}{c}\text { POBLACIONALES } \\
\text { de instrucción }\end{array}$ & $\begin{array}{c}\text { Marro- } \\
\text { quís }\end{array}$ & $\begin{array}{c}\text { Ecuato- } \\
\text { rianos }\end{array}$ & $\begin{array}{c}\text { Marro- } \\
\text { quís }\end{array}$ & $\begin{array}{c}\text { Ecuatoria- } \\
\text { nos } \\
\text { (sin otros) }\end{array}$ & $\begin{array}{c}\text { Ecuatorianos } \\
\text { (con latinoa- } \\
\text { mericanos } \\
\text { complemen- } \\
\text { tarios) }\end{array}$ \\
\hline Hombre & $59.4 \%$ & $47.0 \%$ & $55.8 \%$ & $54.7 \%$ & $50.0 \%$ \\
Mujer & $40.6 \%$ & $53.0 \%$ & $44.2 \%$ & $45.3 \%$ & $50.0 \%$ \\
TOTAL & $100.0 \%$ & $100.0 \%$ & $100.0 \%$ & $100.0 \%$ & $100.0 \%$ \\
\hline 18-24 años & $15.34 \%$ & $14.45 \%$ & $14.3 \%$ & $14.29 \%$ & $13.3 \%$ \\
25-34 años & $35.00 \%$ & $34.22 \%$ & $37.7 \%$ & $36.51 \%$ & $37.3 \%$ \\
35-44 años & $27.30 \%$ & $30.50 \%$ & $36.4 \%$ & $31.75 \%$ & $29.3 \%$ \\
$\begin{array}{l}45 \text { años o más } \\
\text { TOTAL }\end{array}$ & $22.4 \%$ & $20.8 \%$ & $11.7 \%$ & $17.5 \%$ & $20.0 \%$ \\
\hline Sin estudios & $41.5 \%$ & $7.2 \%$ & $10.4 \%$ & $1.6 \%$ & $1.3 \%$ \\
$\begin{array}{l}\text { Primaria / 1r ciclo } \\
\text { secundaria }\end{array}$ & $32.9 \%$ & $33.3 \%$ & $40.3 \%$ & $29.7 \%$ & $35.5 \%$ \\
$\begin{array}{l}\text { 2ndo ciclo secun- } \\
\text { daria }\end{array}$ & $19.3 \%$ & $47.7 \%$ & $24.7 \%$ & $54.7 \%$ & $50.0 \%$ \\
$\begin{array}{l}\text { Estudios Universi- } \\
\text { tarios }\end{array}$ & $6.3 \%$ & $11.8 \%$ & $24.7 \%$ & $14.1 \%$ & $13.2 \%$ \\
TOTAL & $100.0 \%$ & $100.0 \%$ & $100.0 \%$ & $100.0 \%$ & $100.0 \%$ \\
\hline
\end{tabular}

Fuente: Idescat, explotación estadística del Padrón de 2010 (Datos poblacionales por sexo y edad); Encuesta Nacional de Inmigrantes 2007 (Datos poblacionales por nivel de estudios) y Encuesta de Redes Personales CASREDIN 2010 (muestra). 
Los datos informan sobre las características socio-demográficas del ego (la persona encuestada) y sus prácticas asociativas ${ }^{5}$, de los alteri (30 personas nombradas a través de un generador flexible de nombres) ${ }^{6}$, de la relación entre ego y alter, y de las relaciones existentes entre cada par de alteri. En segundo lugar, se han realizado entrevistas semi-estructuradas y narrativas a 18 informantes seleccionados de la muestra anterior, considerando la estructura de su red personal (concretamente, se ha buscado intencionalmente la presencia de entrevistados con los diferentes tipos de red resultantes del análisis de clasificación llevado a cabo) y el grado de vinculación con las asociaciones (es decir, la presencia en ellos de personas con diferente grado de implicación: no participantes, participantes pasivos, activos y dirigentes); manteniendo al mismo tiempo la distribución por cuotas (por nacionalidad y municipio) de la encuesta de redes personales.

Se trata, por lo tanto, de un diseño secuencial con una primera fase cuantitativa mediante cuestionario, cuyo análisis permite conocer la estructura de las redes personales ${ }^{7} \mathrm{y}$, mediante análisis de conglomerados, identificar tres tipos de estructuras que también sirven de base para seleccionar casos específicos que son posteriormente entrevistados. Las entrevistas permiten, por un lado, validar la información obtenida por cuestionario sobre las características de las redes y profundizar en las mismas; por otro, identificar cómo los significados atribuidos a las redes contribuyen a explicar la creación, mantenimiento y ruptura de relaciones hasta desembocar en la red analizada. Los materiales cuantitativos y cualitativos han sido analizados separadamente e integrados en la interpretación de los resultados. La pertinencia de nuestra elección se justifica, siguiendo los

${ }^{5}$ Concretamente, se pregunta si el entrevistado/a participa en alguna asociación de tipo religiosa, de ocio o deportiva, cultural, política, social o sindical, profesional, educativa o de padres, relacionada con la inmigración u otras (en este caso, cuál). En caso de participar en alguna de ellas, se pregunta por el grado de implicación en la asociación (dirigente, activo/a o no activo/a).

${ }_{6}$ Concretamente, la pregunta generadora de los alteri i de la red es: "Por favor, dígame una lista de 30 personas que Usted conozca por su nombre y viceversa con las que ha tenido contacto al menos en los dos últimos años por cualquier medio de comunicación y que además pueda volver a contactarla si fuese necesario. No incluya personas menores de 18 años. Puede ser cualquier persona. Intente incluir gente que sea próxima e importante para Usted. Luego puede incluir personas que no siendo tan cercanas acostumbra a ver mucho. Puede extender su memoria a otras personas. Puede ayudarle pensar en diferentes grupos de personas en diferentes lugares, familia, amigos, compañeros, vecinos, etc.».

7 Es importante tener en cuenta la naturaleza de los datos con los que tratamos en las encuestas de redes personales. El análisis de las estructuras y posiciones puede referirse tanto a relaciones fácticas - los vínculos efectivos - como cognitivas - es decir, los que son percibidos por los actores. Tal sería el caso de las estructuras sociales cognitivas (CSS), en las que se solicita a los participantes informar no solo sobre sus relaciones directas, sino también sobre las percepciones que tienen de las relaciones entre los otros actores (Krackhard 1987; Kilduff, Crossland, Tsai y Krackhardt 2008). De forma similar, en el caso de las redes personales, como es nuestra investigación, no sólo medimos las relaciones del ego con los Alteri, sino también las relaciones que ego percibe que hay entre los alteri nombrados. Así, aunque analizamos la red existente entre los alteri que conforman el entorno relacional de los egos como si fuese una red de relaciones fácticas, en realidad se trata de la representación cognitiva del ego sobre la red de relaciones entre los alteri de su entorno.

EMPIRIA. Revista de Metodología de Ciencias Sociales. N. ${ }^{\circ}$ 26, julio-diciembre, 2013, pp. 89-116. ISSN: 1139-5737, DOI: 10.5944/empiria.26.7154 
términos planteados por Verd y López Roldán (2008), por (i) eficiencia teórica, en tanto que permite ofrecer una explicación integrada de cómo los procesos subjetivos intervienen en la conformación de las redes personales, y por (ii) la eficiencia metodológica de un diseño secuencial, en el que los resultados de la fase cuantitativa permiten seleccionar los casos objeto de análisis intensivo.

El siguiente cuadro resume la aproximación empírica que nos posibilitan las técnicas cuantitativas y cualitativas en las dimensiones de análisis consideradas.

Tabla 2. Resumen de la aplicación empírica de las diferentes técnicas de investigación en las dimensiones de análisis

\begin{tabular}{|c|c|c|c|}
\hline & \multicolumn{2}{|c|}{ Técnicas de investigación } \\
\hline & & Cuantitativas & Cualitativas \\
\hline \multirow{3}{*}{ 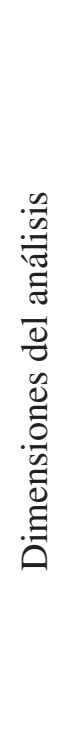 } & Estructura & $\begin{array}{l}\text { Características de ego } \\
\text { y alteri. } \\
\text { Densidad y cohesión de } \\
\text { la red personal. } \\
\text { Construcción de tipolo- } \\
\text { gía. }\end{array}$ & $\begin{array}{l}\text { Validación de relaciones me- } \\
\text { didas. } \\
\text { Detalles de las características } \\
\text { de los alteri y de las relaciones. } \\
\text { Ampliación de la red } \\
\text { Contextualización de los com- } \\
\text { ponentes y subgrupos de la red. }\end{array}$ \\
\hline & Significados & $\begin{array}{l}\text { Aproximación al tipo de } \\
\text { vinculación relacional: } \\
\text { Características del inter- } \\
\text { cambio asociativo (tipo } \\
\text { de asociación). } \\
\text { Proximidad percibida } \\
\text { con los alteri. }\end{array}$ & $\begin{array}{l}\text { Visión «insider» de la red: } \\
\text { Profundización en el valor sub- } \\
\text { jetivo de las relaciones (instru- } \\
\text { mental/expresivas; grupo/co- } \\
\text { munidad/ciudad; hacia ego/el } \\
\text { propio grupo/fuera del grupo). }\end{array}$ \\
\hline & Dinámica & $\begin{array}{l}\text { Antigüedad del proceso } \\
\text { migratorio. } \\
\text { Índices de variación de } \\
\text { la red. }\end{array}$ & $\begin{array}{l}\text { Procesos de interacción. } \\
\text { Evolución de la red como } \\
\text { efecto del valor atribuido a las } \\
\text { relaciones. }\end{array}$ \\
\hline
\end{tabular}

Fuente: Elaboración propia.

\section{RESULTADOS}

Los resultados de la investigación empírica se exponen en tres apartados, que corresponden a las tres dimensiones o ámbitos de la realidad social presentados en la introducción (estructura, significados y dinámica), prestando atención al impacto de la participación asociativa en cada una de estas dimensiones y en la relación entre ellas. 


\section{La estructura y posiciones de la red}

Con el fin de ver las diferentes formas de asentamiento y acomodación de la población inmigrada en Cataluña hemos realizado un análisis de clasificación jerárquica de sus redes sociales ${ }^{8}$. Las variables introducidas en el análisis se derivan de las dinámicas que los diferentes enfoques teóricos señalan como relevantes en la configuración de los procesos de integración (asimilación, multiculturalismo, transnacionalismo). Concretamente, hacen referencia a la composición étnica de los alteri, a su localización geográfica y al lugar de conocimiento (país de origen o destino) en el caso de alteri co-étnicos, y se detallan en la Tabla 1.

El análisis de conglomerados muestra tres patrones de asentamiento. El primero es el «transnacional»; se caracteriza por una gran presencia en sus redes (más del 50\%) de personas residentes en el país de origen del ego. El segundo es el «mixto», y destaca especialmente por el hecho de tener unas redes bastante equilibradas y diversas, con una presencia elevada de alteri autóctonos. Finalmente, el tercer tipo es el del «enclave étnico»; se caracteriza por la presencia de una proporción importante de alteri del mismo origen en el país de destino (tanto contactos mantenidos del país de origen como contactos nuevos).

Tabla 3. Tipología de redes

\begin{tabular}{|c|c|c|c|c|c|c|c|}
\hline Tipología & & $\begin{array}{c}\% \\
\text { Medio } \\
\text { alteri au- } \\
\text { tóctonos } \\
\text { en el país } \\
\text { de destino }\end{array}$ & $\begin{array}{c}\% \\
\text { Medio alteri } \\
\text { del mismo } \\
\text { origen en } \\
\text { el país de } \\
\text { destino } \\
\text { mantenido/a }\end{array}$ & $\begin{array}{c}\% \\
\text { Medio } \\
\text { alteri del } \\
\text { mismo } \\
\text { origen en } \\
\text { el país de } \\
\text { destino } \\
\text { nuevo/a }\end{array}$ & $\begin{array}{c}\% \\
\text { Medio } \\
\text { alteri de } \\
\text { otros orí- } \\
\text { genes en } \\
\text { el país de } \\
\text { destino }\end{array}$ & $\begin{array}{c}\% \\
\text { Medio } \\
\text { alteri } \\
\text { en el } \\
\text { país de } \\
\text { origen }\end{array}$ & $\begin{array}{c}\% \\
\text { Medio } \\
\text { alteri } \\
\text { en } \\
\text { otros } \\
\text { países }\end{array}$ \\
\hline \multirow{2}{*}{$\begin{array}{l}\text { 1.Transnacional } \\
\qquad(\mathrm{n}=55)\end{array}$} & Media & 6.55 & 10.30 & 22.91 & 3.76 & 50.61 & 5.88 \\
\hline & $\begin{array}{l}\text { Desv. } \\
\text { típ. }\end{array}$ & 6.57 & 7.78 & 14.00 & 4.67 & 16.69 & 8.41 \\
\hline \multirow{2}{*}{$\begin{array}{l}\text { 2. Mixto } \\
(n=56)\end{array}$} & Media & 37.08 & 17.50 & 10.89 & 7.14 & 22.98 & 4.40 \\
\hline & $\begin{array}{c}\text { Desv. } \\
\text { típ. }\end{array}$ & 17.65 & 13.18 & 8.47 & 6.21 & 14.08 & 6.26 \\
\hline
\end{tabular}

${ }^{8}$ El método de aglomeración de grupos utilizado ha sido el propuesto por Ward (1963), basado en priorizar aquellas agregaciones que minimizan la varianza intra-grupo. 


\begin{tabular}{|c|c|c|c|c|c|c|c|}
\hline Tipología & & $\begin{array}{c}\% \\
\text { Medio } \\
\text { alteri au- } \\
\text { tóctonos } \\
\text { en el país } \\
\text { de destino }\end{array}$ & $\begin{array}{c}\% \\
\text { Medio alteri } \\
\text { del mismo } \\
\text { origen en } \\
\text { el país de } \\
\text { destino } \\
\text { mantenido/a }\end{array}$ & $\begin{array}{c}\% \\
\text { Medio } \\
\text { alteri del } \\
\text { mismo } \\
\text { origen en } \\
\text { el país de } \\
\text { destino } \\
\text { nuevo/a }\end{array}$ & $\begin{array}{l}\% \\
\text { Medio } \\
\text { alteri de } \\
\text { otros orí- } \\
\text { genes en } \\
\text { el país de } \\
\text { destino }\end{array}$ & $\begin{array}{c}\% \\
\text { Medio } \\
\text { alteri } \\
\text { en el } \\
\text { país de } \\
\text { origen }\end{array}$ & $\begin{array}{c}\% \\
\text { Medio } \\
\text { alteri } \\
\text { en } \\
\text { otros } \\
\text { países }\end{array}$ \\
\hline \multirow{2}{*}{$\begin{array}{l}\text { 3. Enclave } \\
\text { étnico } \\
(\mathrm{n}=42)\end{array}$} & Media & 13.91 & 22.43 & 39.06 & 12.62 & 8.81 & 3.17 \\
\hline & $\begin{array}{c}\text { Desv. } \\
\text { típ. }\end{array}$ & 12.36 & 18.29 & 20.27 & 15.97 & 9.45 & 5.75 \\
\hline \multirow{2}{*}{$\begin{array}{c}\text { Total } \\
(\mathrm{n}=153)\end{array}$} & Media & 19.74 & 16.27 & 22.94 & 7.43 & 29.02 & 4.60 \\
\hline & $\begin{array}{c}\text { Desv. } \\
\text { típ. }\end{array}$ & 18.78 & 14.09 & 18.21 & 10.14 & 22.13 & 7.03 \\
\hline
\end{tabular}

Fuente: Encuesta de Redes Personales CASREDIN 2010.

Los resultados de la encuesta permiten resaltar otros aspectos relativos a la estructura de las redes. Las del tipo transnacional, en oposición a las del mixto, son más densas y cohesivas (tienen un mayor grado y proximidad media); también son redes más familiares, con una mayor presencia de familia extensa, así como de personas de la misma confesión religiosa. En cambio, las redes del tipo del enclave étnico son menos familiares, y se ubican en mayor medida en el mismo barrio y municipio en el que reside ego. También observamos como los tres tipos tienen un comportamiento asociativo diferente. Mientras que el transnacional es el que menos participa, el tipo del enclave étnico lo hace un poco más y más activamente (con mayor intensidad e implicación). Además, como observamos en el gráfico 1, el tipo de gente que se conoce en el entorno asociativo es diferente en los diferentes casos: las personas con redes de tipo mixto participan con personas autóctonas en mayor medida, mientras que las personas con redes de tipo transnacional y sobre todo de enclave étnico participan con personas de su mismo origen. 
Gráfico 1. Media de alteri que participan en la misma asociación que ego (entre aquellos egos que participan), según el origen de los alteri y el tipo de red de los egos

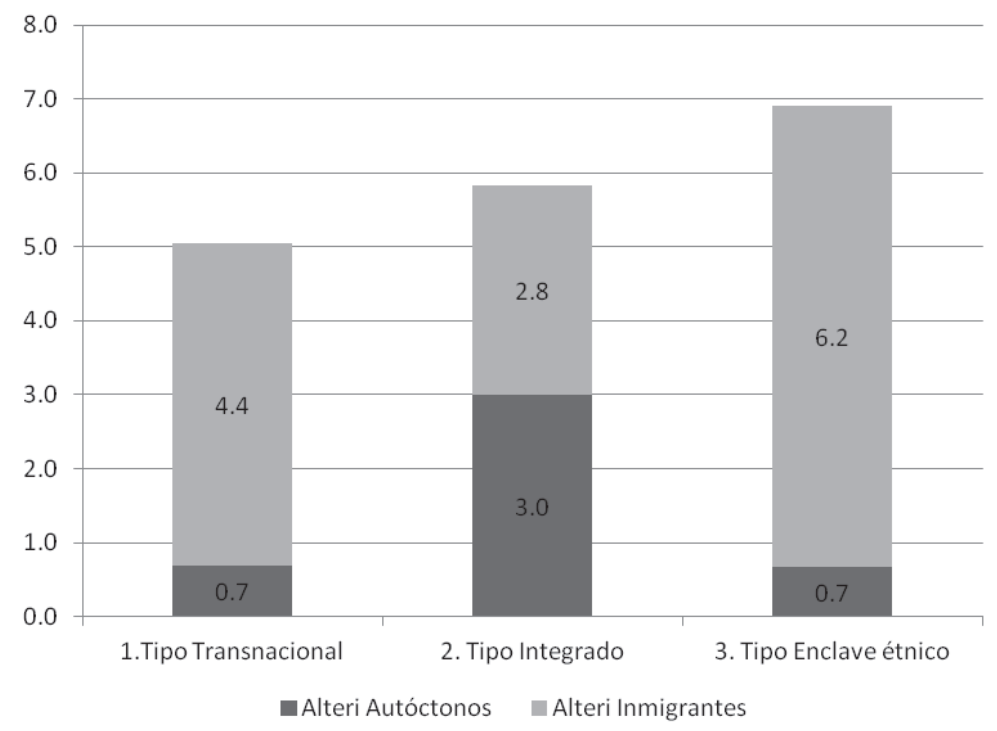

Fuente: Encuesta de Redes Personales CASREDIN 2010.

Los datos sugieren, pues, que existe una conexión entre, por un lado, la intensidad de la participación y la relevancia (numérica) y naturaleza (autóctonos vs. inmigrantes) de su entorno relacional, y, por el otro, el tipo de redes que se desarrollan en la sociedad de acogida en general. Sin embargo, en todos los casos este entorno es muy local: el $99,1 \%$ de los alteri con los que se comparte la actividad asociativa residen en la sociedad de acogida.

La información de las entrevistas también ha aportado elementos relevantes para el estudio de las estructuras de las redes de la población inmigrada. En primer lugar, lo cualitativo nos ha permitido corregir errores registrados durante el trabajo de campo y re-interpretar algunos de los índices de medida. Gracias a ello, por ejemplo, hemos podido identificar la tendencia de algunos entrevistados a indicar alteri de estatus elevado y/o de relevancia pública (Molina, 2005), con los que puntualmente se ha tenido contacto, pero que no forman parte de la red principal, cotidiana y proveedora de apoyo social del ego; o bien identificar vínculos de apoyo social con personas autóctonas que pueden no necesariamente ser indicativos de asimilación o integración relacional, sino más bien de dependencia institucional, cuando estos vínculos se refieren a profesionales del ámbito social (médicos, psicólogas, trabajadoras sociales, educadoras, etc.) que acompañan una situación de vulnerabilidad relacional (Bonet, 2006).

En segundo lugar, la información cualitativa nos ha permitido profundizar en la identificación del entorno relacional de los egos, añadiendo otros alteri no identificados en el cuestionario (es el caso, por ejemplo, de familiares tan cerca- 
nos que, por obvios, al entrevistado no se le ocurre mencionar, o de relaciones «negativas», como pueden ser ex-parejas) o bien contactos específicos del entorno asociativo, que, al ser a veces vínculos débiles quedan excluidos de la lista de 30 mencionados en el cuestionario. Esta aproximación a las redes, concretamente, nos ha permitido observar una importante diferencia entre aquellas personas que participan en asociaciones en función de su nivel de implicación: Los dirigentes (es decir, personas con una posición de liderazgo en organizaciones) desarrollan una doble red, pues su actividad asociativa les introduce también en un entorno organizacional e institucional más amplio y diverso que el espacio inmediato de los miembros de base de la entidad a la que pertenecen, situándose así en una poderosa situación de intermediación.

Finalmente, las entrevistas, mediante la visualización y comentario de la red resultante del cuestionario, nos han facilitado entender el contexto que configura la forma y estructura de las redes, situando los alteri en relación a los dominios de actividad del ego (McCarty, Molina, Aguilar y Rota 2007).

\section{Gráfico 3. Ejemplo de red comentada y trabajada durante una entrevista}

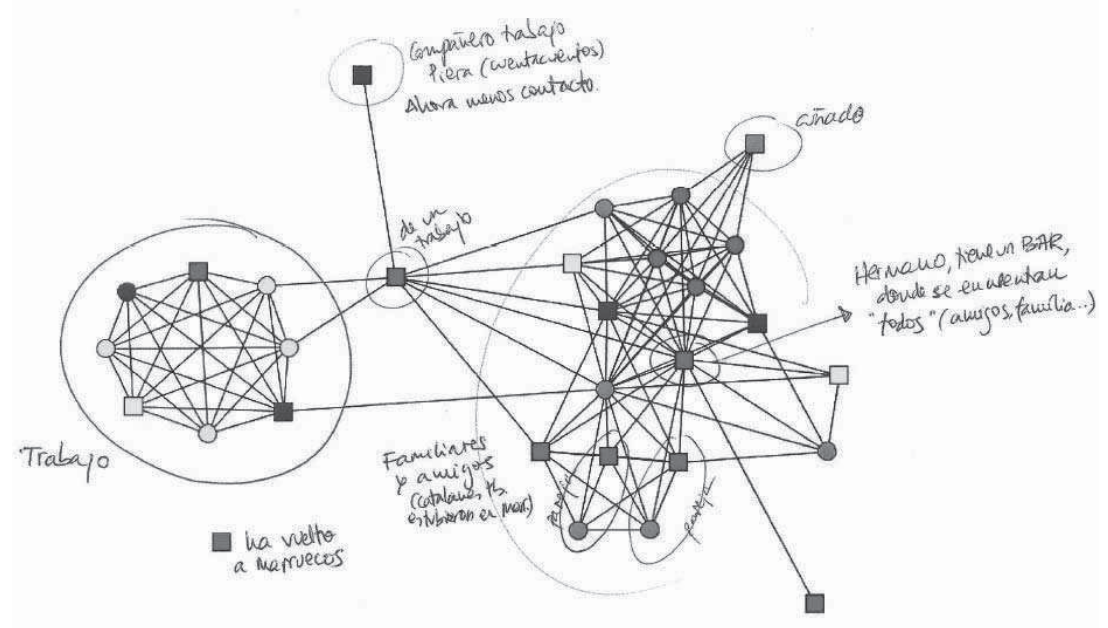

Fuente: Encuesta de Redes Personales CASREDIN 2010.

\section{Los significados de las relaciones}

La vinculación instrumental con los alteri del entorno asociativo entre los individuos del tipo transnacional también se apoya en los datos referentes al tipo de participación: Las personas con una red de tipo transnacional tienden a participar en asociaciones prestadoras de servicios, entidades del tercer sector social que ofrecen ayuda y asistencia a personas inmigradas o con pocos recursos, como pueden ser escuelas de adultos o grupos de orientación laboral, entre otros. En cambio, las personas con redes de tipo mixto o étnico participan más en asocia- 
ciones de tipo expresivo, en las cuales el fin principal recae en la sociabilidad y el grupo, como pueden ser asociaciones culturales, religiosas, de ocio o deportivas.

Finalmente, los datos cuantitativos nos permiten construir índices de proximidad, con los cuales constatamos una vez más que el vínculo afectivo entre los individuos con una red de tipo transnacional con las personas con las que se comparte la actividad asociativa es más bien débil, pues la presencia de alteri con menos proximidad afectiva es mayor, mientras que el perfil mixto es el que siente una proximidad afectiva mayor con los alteri de su entorno asociativo.

Tabla 4. Proporción de alteri con diferentes niveles de proximidad afectiva entre ego y los alteri según el tipo de red del ego

\begin{tabular}{ccccc}
\hline & $\begin{array}{c}\text { 1. Red } \\
\text { transnacional }\end{array}$ & 2. Red mixta & $\begin{array}{c}\text { 3. Red del enclave } \\
\text { étnico }\end{array}$ & Total \\
\hline $\begin{array}{c}\text { Nada o bastante } \\
\text { próximos }\end{array}$ & $21.6 \%$ & $10.1 \%$ & $13.1 \%$ & $14.7 \%$ \\
Próximos & $47.4 \%$ & $28.3 \%$ & $60.7 \%$ & $47.5 \%$ \\
Muy próximos & $19.6 \%$ & $41.4 \%$ & $20.7 \%$ & $26.4 \%$ \\
Íntimos & $11.3 \%$ & $20.2 \%$ & $5.5 \%$ & $11.4 \%$ \\
Total & $100.0 \%$ & $100.0 \%$ & $100.0 \%$ & $100.0 \%$ \\
\hline
\end{tabular}

Fuente: Encuesta de Redes Personales CASREDIN 2010.

Los datos cualitativos, aunque de diferente naturaleza, aportan elementos que apoyan lo interpretado hasta el momento y nos permiten contextualizar el análisis en el marco del significado que los individuos atribuyen a su entorno relacional. Observamos, de esta forma, como en el tipo transnacional no sólo se mantiene en la red una proporción mayor de personas residentes en el país de origen, sino que además se les atribuye una importancia mayor que a la gente residente en el país de acogida. La densidad de las redes de este colectivo visibiliza la existencia de una comunidad muy cohesiva, con fuertes dinámicas de apoyo, que refuerzan la identificación con el «allá». Las entrevistas muestran especialmente el apoyo expresivo y afectivo que reciben de sus alteri en el país de origen (bien sean familia o amigos):

«Con estos chicos que te digo que son de Ecuador... O sea que yo (...) cojo el teléfono y les pido un favor. Pero ellos, claro, no me han visto unos 6 o 8 años. Pero tenemos la misma confianza. Y yo lo he comprobado. E igente que vive en Ecuador? 1 Claro, gente que vive en Ecuador. Que yo les llamo y les pido un favor, o que me vengan haciendo... encantados, eh? Igual, ellos me piden un favor y... yo cuento con ellos. Y ellos cuentan conmigo. E O sea, aunque haya distancia... 1 Si, eso no tiene nada, eh, nada, nada que ver»9

${ }_{9}$ Nota sobre la transcripción: «E» indica la intervención del/a entrevistador/a, mientras que, en caso de diálogo, la respuesta del informante va precedida por «1».

EMPIRIA. Revista de Metodología de Ciencias Sociales. N. ${ }^{\circ}$ 26, julio-diciembre, 2013, pp. 89-116. ISSN: 1139-5737, DOI: 10.5944/empiria.26.7154 
Estos individuos no tienen mucho tiempo y/o ganas de tejer un nuevo entorno relacional local. En algunos casos esto se debe a un proyecto de retorno (siempre presente pero no materializado), que conlleva el sentimiento de estar «de paso» y de querer regresar a su país. En otros, sin problematizar esta situación, naturalizan el hecho de que «su gente» se encuentre allá. En este contexto, para los individuos con redes transnacionales el entorno asociativo tiene un valor más bien débil, que no genera redes de confianza:

«E ¿En qué cosas cuentas con la gente de la asociación? 1 Yo... pero para decirles cosas así como lo que me pasa, no» (Asociada en entidad étnica recreativa).

En definitiva, considerando los datos cualitativos y cuantitativos, vemos como el entorno asociativo, para las personas con este tipo de red, tiene un valor más bien instrumental, se «utiliza» para la obtención de apoyo en cuestiones concretas prácticas, mientras que el apoyo expresivo y afectivo se obtiene a través de los vínculos (mayormente familiares) con personas que residen en el país de origen ${ }^{10}$.

A diferencia de los del tipo transnacional, entre los individuos con redes tanto mixtas como de enclave étnico, el entorno asociativo tiene valor para los entrevistados como un espacio de sociabilidad, que les hace sentir que son «activos», hacen cosas y conocen gente, generando así un círculo de amistades que les acompañan, como idea opuesta a la de una sociedad anónima en la que uno se encuentra sólo/a. La participación en organizaciones u asociaciones de cualquier tipo significa ser reconocido como miembro parte de un grupo o colectividad:

«Si he de responder por qué estoy en una asociación es porque me faltaba algo, algo, eh..., en el que añoraba muchísimo ¿no? que era este contacto, ah, bueno, el, el compartir con la gente, al, y rodearte...aterricé por el azar en esta asociación cuando yo llegué y bueno, a día de hoy estoy aquí, es forma parte, forma parte de mi vida» (Asociada en entidad étnica de ayuda mutua y prestación de servicios)

Sin embargo, también encontramos algunas diferencias en el valor que se otorga a los vínculos asociativos entre los individuos con redes de tipo mixto o del enclave étnico. Así, además del ocio y la diversión que se pueda obtener del entorno relacional asociativo, entre los primeros la participación en asociaciones significa formar parte de la vida social del pueblo o ciudad o de la comunidad general. ${ }^{11}$

${ }^{10}$ Los vínculos familiares y asociativos no son completamente excluyentes, pero sólo un $16,7 \%$ de los alteri del entorno asociativo son familiares; el 11,8\% en el caso de los individuos con redes transnacionales.

${ }^{11}$ En este tipo, el contacto intercultural se presenta frecuentemente de forma naturalizada:

«E y ¿la otra gente ecuatoriana crees que también le es fácil hacer amigos de aquí, españoles, catalanes? 1 yo creo que si porque ahora mismo se ve mucha mezcla ya, bueno hoy en día ya, 
«Si yo realmente me siento a gusto en este país y quiero formar parte de este país y tengo la, la sensación que llevo más de cuarenta años pues una manera bueno también de hacer país es participando políticamente (...) y supongo que la vinculación con la entidad también hace que realmente te involucres más.» (Asociada en partido político).

En cambio, entre los segundos, la participación en asociaciones (sobre todo en asociaciones de tipo étnico, formadas por personas inmigradas) refuerza la comunidad étnica como grupo de referencia.

«E: Y, que dirías que, ¿cuál es la, lo que aportan las asociaciones? ¿por qué son útiles? 1: Yo creo que el calor de su propia nación, ¿no? De encontrarse con sus propias costumbres, con esos hábitos, de recordar cosas; pero yo creo que lo que buscan es un pedacito de su país, eso es lo que creo que se busca; el sentirse acogido, el saber que aquí hay una seguridad.» (Asociado en entidad étnica cultural y recreativa).

De esta forma la participación en asociaciones genera y refuerza una identidad grupal de base étnica, en un entorno que también tiene valor por su capacidad de prestar apoyo en un espacio fraternal con fuertes dinámicas de ayuda mutua, y sirve como protección ante la soledad y el aislamiento.

«Mi hermano me dijo, mira como te vas a sentir sola, lo único que te digo es que te refugies en la asociación, que te van a dar cobijo, que te van a escuchar, porque lo vas a pasar mal, así que será tu refugio. Así que lo hice tal cual.» (Asociada en entidad étnica de ayuda mutua e incidencia política).

Por otro lado entre la población con redes de tipo étnico, en algunos casos la participación en asociaciones, especialmente entre quienes participan más intensamente, se rige por motivaciones más comunitarias. Con la voluntad de crear un espacio propio para el colectivo, buscan generar espacios de encuentro, visibilizar el colectivo y trabajar por él políticamente.

"Queremos dar a conocer que somos del, del [pueblo], vivimos aquí y somos unas personas y también aquellas personas que conocen que hay, hay muchas personas que no conocen de nosotros casi nada.» (Asociado en entidad étnica cultural y de incidencia política).

\section{Lo longitudinal y lo dinámico}

A pesar de no disponer de datos longitudinales, la fotografía que hemos obtenido en un análisis transversal permite observar algunos indicadores relacionados con la dimensión temporal de las redes.

se ven españoles, ecuatorianos y pa'rriba, pa'bajo, en los colegios mismo, (...) Es que además es inevitable si, si estás en el trabajo vas a tener de todo, si te vas de fiesta igual, si conoces a un amigo él conoce a otro «.

EMPIRIA. Revista de Metodología de Ciencias Sociales. N. ${ }^{\circ}$ 26, julio-diciembre, 2013, pp. 89-116. ISSN: 1139-5737, DOI: 10.5944/empiria.26.7154 
Uno de ellos es el tiempo que llevan residiendo los informantes en la sociedad de acogida. En este caso (Tabla 3) observamos como las personas que integran el tipo transnacional son las que llevan menos tiempo residiendo en Cataluña, lo que puede explicar parcialmente que su red mantenga tanta gente en el país de origen.

Tabla 5. Media de años de residencia en Cataluña según el tipo de red de los egos

\begin{tabular}{cccc}
\hline & Media & $\mathrm{N}$ & Desv. típ. \\
\hline 1. Transnacional & 6.05 & 55 & 3.93 \\
2. Mixto & 8.73 & 56 & 4.31 \\
3. Enclave étnico & 8.38 & 42 & 6.19 \\
Total & 7.67 & 153 & 4.90 \\
\hline
\end{tabular}

Fuente: Encuesta de Redes Personales CASREDIN 2010.

Por otro lado, las redes de las personas de tipo transnacional son las que han variado menos. Están formadas por relaciones más antiguas (pues se mantienen relaciones - eminentemente familiares - con el país de origen), aunque las relaciones que han creado en el país de acogida son muy nuevas (la antigüedad media es de 3,6 años, frente a los 4,6 de los otros dos tipos). Como vemos en la tabla 4, las relaciones que han creado específicamente en el entorno asociativo también están muy poco asentadas en la red, lo que refuerza la inestabilidad de la red de contactos locales de estos individuos. Las redes del tipo mixto reconstruidas en el país de destino, en cambio, son las que están más asentadas, igual que las relaciones específicas del ámbito asociativo (sólo un 26,5\% de estas relaciones tienen menos de 2 años). En cambio, las redes del tipo enclave son las que han ido variando más en el tiempo (la media es de 12,8 años de conocimiento o relación, respecto a los 14,1 de los del tipo mixto y los 17,3 del tipo transnacional). 


\section{Tabla 6. Distribución de los Alteri conocidos a partir del inicio del proceso migratorio y que participan en la misma asociación que Ego, en franjas de antigüedad de los contactos, según el tipo de red de Ego}

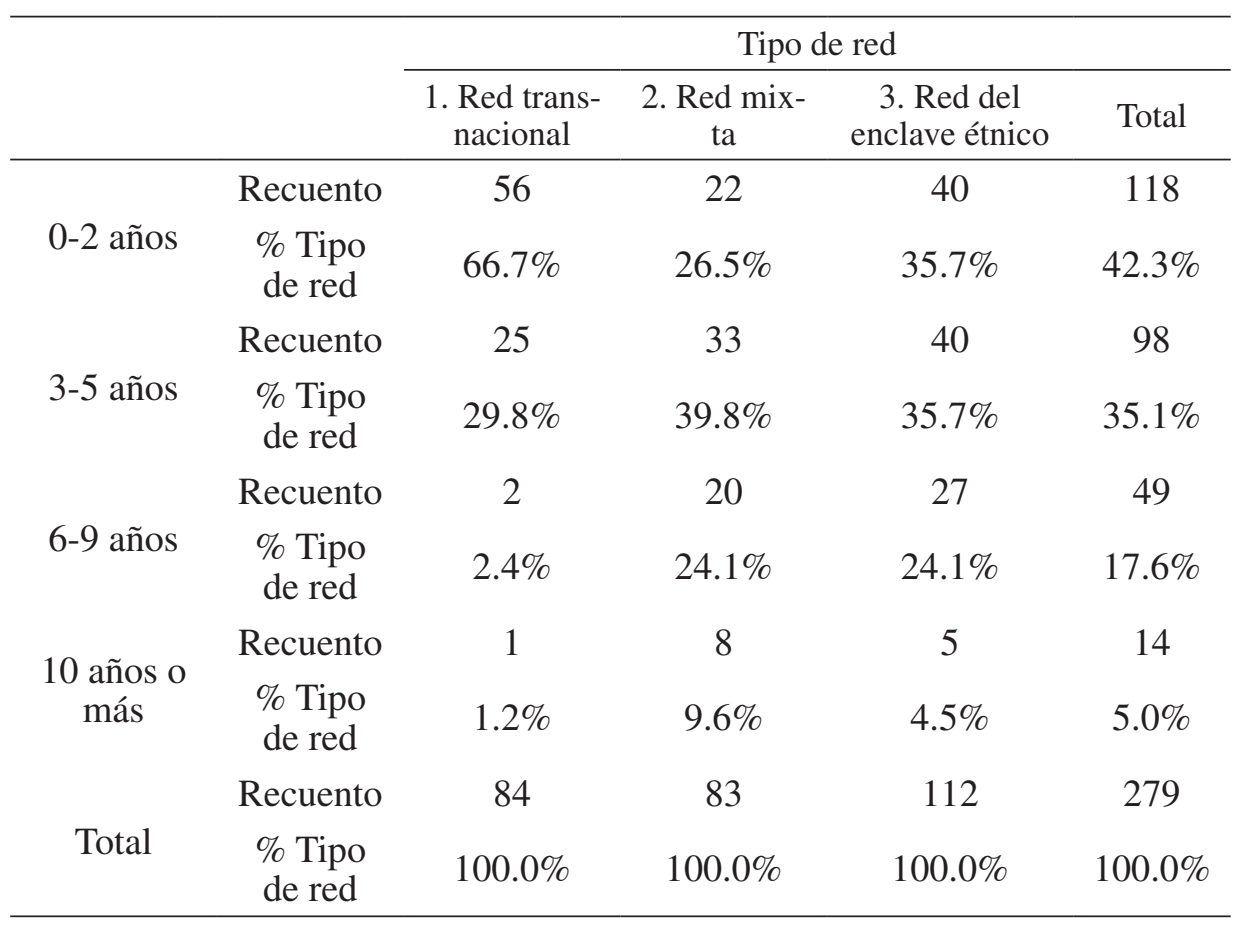

Fuente: Encuesta de Redes Personales CASREDIN 2010.

Los datos cualitativos nos permiten, por un lado, un estudio más detallado de los procesos de interacción, es decir, de cómo se inician las relaciones, qué prácticas de interacción sostienen las relaciones, y cómo acaban «encajando» en la estructura de la red personal, generando patrones de cambio diferentes en función de estos procesos. Así, por ejemplo, hemos podido observar la importancia del mecanismo de la «bola de nieve» (es decir, las oportunidades de nuevos contactos que ofrecen los existentes). Por otro, el tipo de entrevista narrativa con el que trabajamos en las entrevistas permite entender cómo el significado que se otorga a las relaciones establecidas en el mundo asociativo moldea estos cambios en la red personal de las personas entrevistadas.

Así, las personas con redes de tipo transnacional, en general, son las que tienen unas redes más estáticas y menos cambiantes. Los medios telemáticos permiten mantener un contacto cotidiano, asiduo y regular con las personas co- 
nocidas que residen en su país de origen, siguiendo el día a día de la gente allá, lo que facilita el mantenimiento de la red en el origen:

«Eh, en el correo también, es un medio bastante importante el Facebook, es una red social bastante importante, E Ajá. Y así sabes que es lo qué están haciendo... 1 Que es lo que están haciendo, que, o sea como están actualmente porque las fotografías es lo que tú le ves le dices -mira como está ahora, con el pelo así-, que...con bueno, es que se sabe de todo porque las fotos es el fiel reflejo de las personas. Te ves a ver si ha adelgazado, cómo está, (risas) eso es lo fundamental.»

Este contacto con personas residentes en sus países de origen es lo que permite la creación de un espacio social transnacional a partir del cual las personas migrantes crean y recrean sus vidas simultáneamente en más de una sociedad (Parella y Cavalcanti 2008).

Sin embargo, en este grupo encontramos dos situaciones diferentes: Por un lado, encontramos las personas ancladas en el origen, para quienes el paso del tiempo no conlleva un cambio substantivo en la estructura de sus redes. En estas situaciones, las asociaciones no tienen suficiente fuerza como para cambiarlas. Debido a la no vinculación expresiva o identitaria, en el caso de participar en ellas, no se convierten en un impulso suficientemente importante para generar un entorno relacional local que pueda «competir» con el grupo de referencia ubicado en el país de origen, pues intervienen poco en la red personal. Por otro lado, encontramos individuos con redes más dinámicas, que se encuentran en este grupo básicamente porque hace muy poco tiempo que residen en la sociedad de acogida. En estos casos, se observa como la participación en asociaciones impulsa y/o acompaña un proceso de cambio en las redes, hacia estructuras de tipo mixto o de enclave étnico.

En el tipo mixto, observando el conjunto de sus trayectorias, vemos como se ha producido una diversificación progresiva de las redes, en las que se ha incorporado tanto personas co-étnicas como, especialmente, autóctonas. A diferencia de los transnacionales, los individuos con redes de tipo mixto, igual que las de enclave étnico, pasan por un proceso de distanciamiento o ruptura con la red de contactos en el origen, y de generación de un entorno local ubicado en el país de destino. En este proceso, la participación en asociaciones - en concordancia con lo que apunta la literatura existente- fomenta la generación de nuevas relaciones y la ampliación de las redes existentes, brindando nuevas oportunidades de interacción para la reconstrucción del entorno relacional ${ }^{12}$. Además, el valor

${ }^{12}$ Sin embargo este proceso no se produce en todos los casos. Hemos identificado un subperfil minoritario que no entramos a detallar en el cual la integración se produce por otros ámbitos (laboral o bien familiar - es decir, mediante la creación de parejas mixtas-), a pesar de un tipo de participación más parecido al de los del tipo del enclave étnico, y cuya plasmación en la red personal crea un subgrupo mayormente étnico. 
expresivo dado a las nuevas relaciones es clave para la consolidación de los nuevos entornos relacionales:

«A ver claro, vas haciendo nuevos amigos y conoces un entorno, un pueblo, una serie de gente que haces, que vas perdiendo la gente de la amistad que tenías y vas ganando la que donde estás pero no porque tu decidas dejarla y ya está, Si no porque la distancia o el momento que estás haciendo aquí vas conociendo a gente y esta gente tu participas en las actividades o lo que sea y vas haciendo cosas y vas haciendo amigos.»13(Asociado en ONGs)

Paralelamente, en el caso de la población con redes de tipo mixto, un primer contacto informal con personas autóctonas (mayormente del ámbito educativo, laboral, o del vecindario) permite la entrada en asociaciones no étnicas, que suponen una inmersión en entornos autóctonos; contactos que gracias a la actividad asociativa se mantienen y se solidifican, y que a su vez son una puerta de entrada para nuevas relaciones en entornos «catalanes»:

"[Cuando empecé a participar] Fue un momento de esos que hacías amigos por todas partes; además me apunté al voluntariado, me saqué el carnet de voluntario, eh... bueno, hacía de todo, estaba metido en todo y eso de algún modo me ha abierto las puertas a otras cosas; conocer más gente, conocer el funcionario de turno, conocer las personas.»14 (Asociado en ONGs).

En el caso del tipo enclave étnico, la participación en asociaciones tiende al desarrollo de una red de iguales. Aunque con cierta diversidad en sus trayectorias y en la forma, tipo y momentos de generación de nuevos contactos, en el proceso de conocer nueva gente participan activamente en un proceso creación, consolidación e institucionalización de una comunidad étnica, lo que refuerza la identidad grupal y el sentimiento de pertenencia al grupo étnico:

«Yo vengo aquí, me estudio cultura amazigha en la asociación amazigha, con gente, viene también gente aquí y ponemos asociación aquí también amazigha, pero hay más gente, están haciendo asociaciones amazigha, ahora tenemos mas asociación amazigha y luego hacemos casa amazigha aquí, y de eso empieza a estar... (...) nosotros terminamos eso. No dejamos eso ya está, estamos aquí por trabajar y para comer. No. También para cultura.» (Asociado en entidad étnica cultural y de incidencia política)

\section{CONCLUSIONES}

Este artículo aborda dos objetivos. Por un lado, pretendíamos observar cuál es el impacto de la participación en asociaciones sobre el proceso de integración

\footnotetext{
13 Traducción del catalán.

14 Traducción del catalán.
}

EMPIRIA. Revista de Metodología de Ciencias Sociales. N. ${ }^{\circ}$ 26, julio-diciembre, 2013, pp. 89-116. ISSN: 1139-5737, DOI: 10.5944/empiria.26.7154 
de la población inmigrada en Cataluña. Por el otro, metodológicamente nos planteábamos ejemplificar con una investigación empírica las fortalezas del uso de métodos mixtos en el análisis de redes sociales. Veamos pues por separado las aportaciones en cada uno de ellos.

\section{Conclusiones de contenido substantivo.}

En el plano teórico, los resultados del análisis realizado reflejan los tres patrones de integración de la población inmigrada identificados en la investigación en el campo (transnacional, mixto, enclave étnico) y muestran que, juntamente con los factores que la literatura señala como relevantes en los procesos de integración relacional (participación en el mercado de trabajo, situación jurídica, aprendizaje del idioma, etc.), las asociaciones juegan un papel específico en los mismos. Sin embargo, retomando el debate presentado sobre el efecto de la participación asociativa sobre las redes personales, cabe señalar que este papel no es necesariamente de asimiliación ni de enclave, sino que puede ser uno u otro en función del valor atribuido a las relaciones asociativas, del tipo de asociación y del contexto y proceso en el que se produce esta relación.

Concretamente, la forma en que se participa en asociaciones es un elemento más que refuerza el valor que las personas migrantes atribuyen a sus relaciones. Sintéticamente, en el caso de la población con redes de tipo transnacional, el vínculo con el entorno asociativo (especialmente con organizaciones prestadoras de servicios) es mayormente instrumental, con lo que su impacto en la conformación y dinámica de las redes personales es muy débil. En cambio, para el tipo enclave étnico, las asociaciones (especialmente aquellas de tipo expresivo -religiosas, de ocio, deportivas o culturales-) son instrumentos para la inclusión en un grupo de iguales que refuerza el sentimiento de pertenencia a una comunidad étnica propia, generando así contactos bonding en el sino de esta comunidad recreada a través de las redes. Finalmente, en el tipo mixto las asociaciones (también aquellas de tipo instrumental, cuyo propósito va más allá del disfrute de la sociabilidad en sí misma, como grupos políticos, asociaciones sindicales, profesionales u ONG) son un instrumento para llegar a gente y a realidades nuevas y diferentes, lo cual diversifica sus redes.

Además, en el estudio de las biografías observamos que, aunque no se produce una evolución unidireccional (en algunos casos se produce el cambio de un patrón transnacional a étnico y después mixto, pero en otros casos se pasa directamente al mixto, o bien directamente al del enclave étnico, etc.), existe cierta evolución de unos a otros.

En futuros análisis puede ser de interés estudiar con mayor profundidad la interacción del asociacionismo con los ámbitos laboral y familiar. Esta aproximación podría aportar más complejidad al estudio de la evolución de las redes sociales de la población inmigrada y su evolución en el proceso de asentamiento en la sociedad de acogida. 


\section{Conclusiones metodológicas}

Los método mixtos en redes han sido muy aplicados en diseños de tipo concurrente (Bellotti 2008; Bernardi 2011; Keim et al. 2011) en los que se obtienen datos cuantitativos y cualitativos para los mismos casos (lo que facilita la integración de ambos tipos de datos pero, a su vez, genera tensión entre la obtención de un tamaño muestral suficientemente amplio para comparar estadísticamente los casos y, al mismo tiempo, suficientemente limitado para analizarlos de forma intensiva y contextualizada). La opción por la que hemos optado aquí, habitual en los muestreos por métodos mixtos (Teddlie y Yu 2007), consiste en vincular secuencialmente los criterios de selección de una segunda fase cualitativa $(n=18)$ a una primera cuantitativa $(\mathrm{n}=153)$, de forma que conocemos cómo se distribuyen los casos objeto de análisis en la muestra cuantitativa.

En la investigación que hemos presentado, los métodos cuantitativos nos han ofrecido una «vista general» o panorámica con la que observar la estructura y posiciones de la red, identificando los diferentes tipos de redes y vinculándolos al comportamiento y presencia de sus egos en campos sociales específicos. En esta dimensión del análisis, la capacidad que ofrecen los métodos cualitativos de profundizar sobre el contenido y naturaleza de las relaciones singulares del ego con cada uno de sus alteri, nos han permitido captar detalles que la estandarización «deja escapar», re-interpretar algunos de los indicadores e índices de medida, y comprender el contexto que favorece la forma específica de las redes estudiadas.

En el análisis de los significados de las relaciones, mediante la estandarización de algunos indicadores (como el de intercambio de diferentes tipos de apoyo social, o el tipo de actividades que se realiza en la asociación en la que se participa), nos hemos aproximado de forma indirecta al valor atribuido a los vínculos generados en el entorno asociativo. Las narrativas de los actores nos han permitido profundizar en los significados que para ego tienen tanto el conjunto del entorno relacional (el cual nos da una información muy valiosa para entender el proceso de integración), como el entorno asociativo.

Finalmente, con el estudio del proceso relacional observamos el impacto específico de diferentes entornos sobre el cambio en las redes (en el caso que nos concierne, la participación en asociaciones). Al tratarse de un diseño transversal hemos podido trabajar los datos cuantitativos de forma un tanto limitada, mediante índices de antigüedad y variación de la red. En cambio, los datos cualitativos nos han mostrado las prácticas interactivas concretas, que nos permiten entender cómo, en un contexto dado (en el marco de una estructura de oportunidades marcada por la forma inicial de la red que el proceso migratorio particular moldea, así como por la posición y trayectoria en los diferentes campos sociales), los individuos inmigrados reconstruyen su red de relaciones en un proceso en que el valor que atribuyen a las relaciones marca su evolución.

En definitiva, en este trabajo, la incorporación del estudio (eminentemente cualitativo) de los significados y dinámica de las relaciones en un diseño de in- 
vestigación de tipo mixto nos ha permitido entender el porqué de la estructura que los datos cuantitativos nos muestran.

\section{BIBLIOGRAFÍA}

ARMITAGE, N. (2011): «Exploring cosmopolitan conviviality - a biographical network approach». Jornada d'investigació: «Metodologies de xarxes ego-centrades i completes». Centre d'Estudis Sociològics sobre la Vida Quotidiana i el Treball, Universitat Autònoma de Barcelona. 2/12/2011. [Diapositivas de PowerPoint].

BARNES, J. A. (1954): «Class and Committees in a Norwegian Island Parish», Human Relations, 7: 39-58.

BELLOTTI, E. (2008): «What are friends for? Elective communities of single people», Social Networks, 30: 318-329.

BELLOTTI, E. (2010): «Comment on Nick Crossley/1», Sociologica, Italian Journal of Sociology online, 1/12010: 1-8.

BELLOTTI, E. (2011): «Ties and Narratives. Collecting, analysing and interpreting personal network data with qualitative interviews». Connections. (Enviado).

BERNARDI, L. (2011): «A Mixed-Methods Social Networks Study Design for Research on Transnational Families», Journal of Marriage and Family, 73: 788-803.

BIDART, C.; LAVENU, D. (2005): «Evolutions of personal networks and life events», Social Networks, 27: 359-376.

BIDART, C.; CACCIUTTOLO. (2012): «Combining qualitative, quantitative and structural dimensions in a longitudinal perspective. The case of network influence», Quality and quantity, pp.1-21.

BONET, J. (2006): «La vulnerabilidad relacional: Análisis del fenómeno y pautas de intervención». Redes, Revista Hispana para el análisis de las redes sociales, 11 (2), http://revista-redes.rediris.es. Consulta [10-1-12].

BOTT, E. (1957): Family and social network. Londres, Tavistock.

CARLEY, K. (1997): «Network text analysis: the network position of concepts», en Text Analysis for the Social Sciences: Methods for Drawing Statistical Inferences from Texts and Transcripts, Mahwah, NJ, Lawrence Erlbaum.

COVIELLO, N. (2005): «Integrating Qualitative and Quantitative Techniques in Network Analysis Qualitative Market Research», Qualitative Market Research, 8(1): 39-60.

CROSSLEY, N. (2010a): «The Social World of the Network. Combining Qualitative and Quantitative Elements in Social Network Analysis», Sociologica, Italian Journal of Sociology online, 1/2010: 1-34.

CROSSLEY, N. (2010b); «The Social World of the Network: A Reply to the Comments», Sociologica, Italian Journal of Sociology online, 1/12010: 1-7.

CURTIS, R., FRIEDMAN, A., NEAIGUS, B., JOSE, B., GOLDSTEIN, M., and ILDEFONSO, G. (1995): «Street-level Drug Markets: Network Structure and HIV Risk», Social Networks, 17(3-4): 229-249.

DOMÍNGUEZ, S. (2004): «Estrategias de movilidad social: el desarrollo de redes para el progreso personal», Redes, Revista hispana para el análisis de redes sociales, 7(1), http://revista-redes.rediris.es. Consulta [10-1-12].

DOMÍNGUEZ, S. (2008): «Transnational Ties, Poverty and Identity: Latin American Immigrant Women in Public Housing». Family Relations, 57: 419-430. 
EDWARDS, G. (2010): Mixed-Method Approaches to Social Network Analysis. ESRC National Centre for Research Methods Review paper, disponible en http://eprints. ncrm.ac.uk/842/ [consulta 11-11-2011].

EMIRBAYER, M.; GOODWIN, J. (1994): «Network Analysis, Culture and the Problem of Agency», American Journal of Sociology, 99 (6): 1411-1454.

FEDERICO, A. de (2005): «El análisis dinámico de redes sociales con SIENA. Método, discusión y aplicación», Empiria, Revista de metodología de ciencias sociales, 10: 151-184.

FELD, S. (1982): ««Structural determinants of similarity among associates»», American Sociological Review, 47: 797-801.

FUHSE, J.; MÜTZEL, S. (2011): «Tackling connections, structure, and meaning in networks: quantitative and qualitative methods in sociological network research», Quality \& Quantity, 45: 1067-1089.

GARRETA, J. (1998): «Minories ètniques, associacionisme i integració sociocultural. Papers. Revista de Sociologia, 56, pp 197-230.

GLANVILLE, J. (2004): «Voluntary Associations and Social Network Structure: Why organizacional location and type are important». Sociological Forum, 19 (3): 465491.

GLICK SCHILLER, N. (2008): «Nuevas y viejas cuestiones sobre localidad: teorizar la migración trasnacional en un mundo neoliberal, en "Nuevos retos del transnacionalismo en el estudio de las migraciones"». Observatorio permanente de la inmigración, 19, pp 21-46.

GUALDA, E. (2004): «Actitudes hacia las migraciones y capital social: la participación de los europeos en redes sociales y sus lazos con la mayor o menor aceptación de la población extranjera». Redes, Revista hispana para el análisis de redes sociales, 7 (3), http://revista-redes.rediris.es. Consulta [10-1-12].

HAGAN, J. (1998): «Social Networks, Gender and Immigrant Incorporation: Resources and Constraints», American Sociological Review, 63, (1). pp 55-67.

HEATH, S.; FULLER, A.; JOHNSTON, B. (2009): «Chasing shadows: defining network boundaries in qualitative social network», Qualitative Research, 9: 645-661.

HOLLSTEIN, B. (2011): «Qualitative Approaches», en The Sage Handbook of Social Network Analysis, Londres, Sage: 404-416.

HOPE, P.; EDWARDS, R.; GOULBOURNE, H; SOLOMOS, J. (2007): «Immigration, social cohesion and social capital: A critical review», Critical Social Policy, 27 (24): 24- 49.

JACK, S. L. (2010): «Approaches to studying networks: Implications and outcomes», Journal of Business Venturing, 25(1): 120-137.

KEIM, S.; KLÄRNER, A; BERNARDI, L. (2009): «Qualifying Social Influence on Fertility Intentions. Composition, Structure and Meaning of Fertility-relevant Social Networks in Western Germany», Current Sociology, 57(6): 888-907.

KILDUFF, M.; CROSSLAND, C.; TSAI, W.; KRACKHARDT, D. (2008): «Organizational network perceptions versus reality: A small world after all?», Organizational Behavior and Human Decision Processes, 107: 15-28.

KIRKE, D. M. (2010): «Comment on Nick Crossley/2», Sociologica, Italian Journal of Sociology online, $1 / 2010$.

KNOX, H.; SAVAGE, M.; HARVEY, P. (2006): «Social networks and the study of relations: networks as method, metaphor and form», Economy and Society, 35(1): 113-140. 
KRACKHARDT, D. (1987): «Cognitive Social Structures», Social Networks, 9: 109134.

LAUER, S,R,; YAN, M.C. (2010): «Voluntary Association Involvement and Immigrant Network Diversity», International Migrations, (En prensa: DOI: 10.1111/j.1468-2435.2010.00602.x.).

LLUCH, A. M. (1999): «L'associacionisme dels immigrants», a AA.VV. (1999) Immigrants? Nous ciudadans. Barcelona: CIDOB.

LOZARES, C.; VERD, J. M.; MARTÍ, J.; LÓPEZ ROLDÁN, P. (2003): «Relaciones, redes y discurso: revisión y propuestas en torno al análisis reticular de datos textuales», Revista Española de Investigaciones Sociológicas, 101: 175-200.

LOZARES, C.; VERD, J. M.; LÓPEZ ROLDÁN, P MARTÍ, J.; MOLINA, J.L. (2011): «Cohesión, Vinculación e Integración sociales como formas de Capital social», Redes, Revista hispana para el análisis de redes sociales, 20 (1), http://revista-redes. rediris.es. Consulta [10-1-12].

LUBBERS, M; MOLINA, J.L.; McCARTY, C. (2007): «Personal Networks and ethnic identifications», International Sociology,. 22: 721-741.

LUBBERS, M.; MOLINA, J. L.; LERNER, J.; BRANDES, U.; ÁVILA, J.; McCARTY, C. (2010): «Longitudinal analysis of personal networks. The case of Argentinean migrants in Spain», Social Networks, 32: 91-104.

MARSDEN, P. (1990): «Network Diversity, substructures, and opportunities for contact», en Structures of Power and Constraint: Papers in Honor of Peter M. Blau, Cambridge, Cambridge University Press: 397-410.

MAYA, I. (2001): «Tipos de redes personales de los inmigrantes y adaptación psicológica», Redes. Revista Hispana para el análisis de redes sociales, 1 (4), http://revistaredes.rediris.es. Consulta [10-1-12].

McCARTY, C. (2010): «Comment on Nick Crossley/3», Sociologica, Italian Journal of Sociology online, 1/2010: 1-6.

McCARTY, C. MOLINA, J.L., AGUILAR, C. y ROTA, L (2007): «A Comparison of Social Network Mapping and Personal Network Visualization» Field Methods, 19: $145-162$.

McKETHER, W. L.; GLUESING, J.; RIOPELLE, K. (2009): «From Interviews to Social Network Analysis: An Approach for Revealing Social Networks Embedded in Narrative Data», Field Methods, 21(2): 154-180.

MCPHERSON, J.M.; L. SMITH-LOVIN (1987): «Homophily in voluntary organizations: status distance and the composition of face-to-face groups», American Sociological Review, 52: 370-79.

MIGUEL LUKEN, V; SOLANA, M,: PASCUAL (Dir). (2007): Redes sociales de apoyo: La inserción de la población extranjera, Bilbao, Fundación BBVA.

MISCHE, A. (2003): «Cross-talk in movements: Reconceiving the culture-network link», en Social movements and networks: Relational approaches to collective action, New York: Oxford University Press: 258-281.

MOLINA, J.L. (2005): «El estudio de las redes personales: contribuciones, métodos y perspectivas», 10: 71-105.

MOLINA, J.L., LERNER, J., GÓMEZ MESTRES, S. (2008): «Patrones de cambio de las redes personales de inmigrantes en Cataluña». Redes. Revista Hispana para el análisis de las redes sociales, Vol. 15 (4), http://revista-redes.rediris.es. Consulta [10-1-12].

MORELL, A. (2005): «El papel de las asociaciones de inmigrantes en la sociedad de acogida: cuestiones teóricas y evidencia empírica», Migraciones, 17: 111-142. 
MÚTZEL, S. (2009): «Networks as culturally constituted processes: A comparison of Relational Sociology and Actor-network Theory», Current Sociology, 57: 871-887.

PAHL, R.; SPENCER, L. (2004): «Personal Communities: Not Simply Families of "Fate" or "Choice"», Current Sociology, 52(2): 199-221.

PARDO, I. (2011): «¿Necesitamos bases filosóficas y epistemológicas para la investigación con Métodos Combinados?», Empiria, Revista de Metodología de Ciencias Sociales, 22: 91-112.

PARELLA, S.; CAVALCANTI, L. (2008): «Aplicación de los campos sociales transnacionales en los estudios sobre migraciones»; en «Nuevos retos del transnacionalismo en el estudio de las migraciones». Observatorio permanente de la inmigración, 19: 21-46.

PEDONE, C. (2010): «Cadenas y redes migratorias: propuesta metodológica para el análisis diacrónico-temporal de los procesos migratorios», Empiria, Revista de Metodología de Ciencias Sociales, 19: 101-132.

POPIELARZ, P.; MCPHERSON, J. (1995): «On the Edge or in between: Niche position, Niche overlap, and the duration of voluntary association memberships», American Journal of Sociology, 101: 698-720.

PORTES, A.; RUMBAUT, R. (2010): América inmigrante, Barcelona, Anthropos.

PUTNAM, R. (1993): Making Democracy Work: Civic Traditions in Modern Italy, Princeton, Princeton University Press.

PUTNAM, R. (2000): Bowling Alone: The Collapse and Revival of American Community, New York, Simon and Schuster.

SALVINI, A. (2010): «Symbolic Interactionism and Social Network Analysis: An Uncertain Encounter», Symbolic Interaction, 33(3): 354-388.

SIPI, R. (2000): «Las asociaciones de mujeres, ¿agentes de integración social?», Papers, revista de sociologia, 60: 355-364.

SNIJDERS, T. (2005): «Models for longitudinal network data», en Models and Methods in Social Network Analysis, New York, Cambridge University Press.

TEDDLIE, C.; YU, F. (2007): «Mixed Methods Sampling: A Typology With Examples», Journal of mixed methods research, 1(1): $77-100$.

VERD, J. M.; LÓPEZ ROLDÁN, P. (2008). «La eficiencia teórica y metodológica de los diseños multimétodo», Empiria, Revista de Metodología de Ciencias Sociales, 16: 13-42.

VILLASANTE, T. R.; MARTÍN, P. (2006): «Redes y conjuntos de acción: para aplicaciones estratégicas en los tiempos de la complejida social», Redes, Revista hispana para el análisis de redes sociales, 11(2). Consulta [10-1-12].

WARD, J.H., Jr. (1963): «Hierarchical Grouping to Optimize an Objective Function», Journal of the American Statistical Association, 58(301): 236-244.

WHITE, H. (1992): Identity and control.: A Structural Theory of Social Action. Princeton, NJ: Princeton University Press.

WOLLEBÁK, D.; SELLE, P. (2004): «Passive membership in Voluntary Organizations: Implications for Civil Society, Integration and Democracy», en Investigating Social Capital. Comparative perspectives on Civil Society, Participation and Governance, New Delhi, Sage Publications: 235-256.

WONG, S.; SALAFF, J. (1998): «Network capital: emigration from Hong Kong», The British Journal of Sociology, 49(3): 358-374. 